\title{
The Evaluation of Smile Design by Lay People and Dentists in the UAE
}

\section{Asmaa AlShamsi ${ }^{1, *}$, and Moosa AbuZayda ${ }^{2}$}

${ }^{1}$ DDS, MSc in Prosthodontics, Department of Prosthodontic, Hamdan Bin Mohammed College of Dental Medicine, Mohammed Bin Rashid University of Medicine and Health Sciences, Dubai, UAE

${ }^{2}$ Associate professor of prosthodontic programme, BDS, Dr. Med Dent, Diplomat, German board of prosthodontic, Department of Prosthodontic, Hamdan Bin Mohammed College of Dental Medicine, Mohammed Bin Rashid University of Medicine and Health Sciences, Dubai, UAE

*Corresponding author: Asmaa AIShamsi, DDS, MSc in Prosthodontics, Department of Prosthodontic, Hamdan Bin Mohammed College of Dental Medicine, Mohammed Bin Rashid University of Medicine and Health Sciences, Dubai, UAE, E-mail: dr_ventolin1@hotmail.com

Received: 20 Jan, 2020 | Accepted: 18 Feb, 2020 | Published: 24 Feb, 2020

Citation: AlShamsi A, AbuZayda M (2020) The Evaluation of Smile Design by Lay People and Dentists in the UAE. Int J dent oral health 6(3): dx.doi.org/10.16966/2378-7090.318

Copyright: () 2020 AlShamsi A, et al. This is an open-access article distributed under the terms of the Creative Commons Attribution License, which permits unrestricted use, distribution, and reproduction in any medium, provided the original author and source are credited.

\section{Abstract}

Background and Objectives: Esthetics is characterized primarily by the smile, however, the smile comprises much more than the dental arch. Dental smile design preferences differ from one person to other based on different factors such as: social level, economic level, education level and ethnic origin. There is a lack of similar studies in the UAE.

The purpose of this study is to determine which features of a smile are attractive as rated by lay people and dental professionals in the UAE.

Material and Methods: A questionnaire survey of standardized images of smiles was distributed to 190 dental professionals including under-graduate students at Sharjah University and 190 lay people (teachers, employers, workers and patients relatives). A sample size calculation determined the sample as 380. The participants were not randomly selected and were not a representative sample of the UAE population but a convenience sample. The participants were all adults above the age of 17 years. The questionnaire had 7 separate aesthetic features with between 3 to 6 different standardized computer generated images for each feature. The different features included amount of tooth exposed, lip line height, buccal corridor and midline position.

Results: There were a total of 380 participants with a mean age of 28.6 years (SD 7.9) of which $228(60 \%)$ were female. Significantly more females compared to males preferred a convex smile irrespective of whether or not the upper teeth contacted the lower lip $(p<0.01)$. Females tended to prefer low lip line compared to males but this was at the borderline of significance $(p=0.067)$.

Interestingly, more married respondents preferred the low lip line whereas unmarried respondents were evenly distributed between those liking an average and low lip line $(p<0.05)$. The coincidence of dental and facial midlines would be expected as the preferred choice for both dental professionals and lay people but significantly more lay people preferred the smile that deviated to the right whereas dentists preferred midlines to be coincident $(p<0.001)$. Furthermore, residents of Abu Dhabi, Dubai and Sharjah preferred the coincidence of midlines whereas the lay people from Fujairah preferred the right deviation of the dental midline. Over half the unmarried respondents had a significantly greater preference for midline coincidence but married respondents were more evenly split regarding this aspect of smile design $(p<0.05)$. There were no preference differences for most of the smile design features as judged by dentists and lay people.

Conclusion: There is general agreement between dentists and lay people regarding the most pleasing features of smile design. Females prefer a convex incisal curve that follows lip curvature and tend to prefer a low lip line. Coincidence of facial and dental midlines was expected to be preferred by both dentists and lay people but surprisingly this was not the case as lay people, married respondents and residents from Fujairah prefer a right deviation. Why should this preference for a smile with a deviated dental midline be regarded as attractive requires further research but may be influenced by tribal or other cultural factors.

Keywords: Esthetic; Lay people; Dentists; Smile design; UAE population; Lip line

\section{Introduction}

Dental appearance is considered an important feature in determining the attractiveness of a face, thus it influences human social interactions [1,2]. A patient's smile expresses a feeling of success, affection, sensuality and courtesy and reveals self-confidence. The smile, in particular, plays a significant part in determining the first impression of an individual [2]. The smile is more than a method of communicating; it's a mean of socialization and attraction. Different factors affect the overall esthetic and smile, including tooth shape, position, and quality of restoration, color and general arrangement of dentition [3]. The harmony of the smile is determined not only by the shape, the position, and the shade of the teeth but also by the gingival tissues. Gingival visibility depends on the position of the smile line, which is defined as the relationship between the upper lip and the visibility of gingival tissues and teeth [4]. Although any factor could 
be considered separately, they are considered esthetically as a unit, in terms of symmetry and harmony. A youthful smile is defined as full display of maxillary incisor crowns, with 1-2 mm of gingival margin. Usually, females tend to show 1-2 mm more of gingival tissue than males [5].

Smile is a person's ability to express a range of emotion with the structure and movement of the teeth and lips. Smile has been classified as high, average and low by Tjian AH, et al. [2]. High smile shows complete display of cervico-incisal length of maxillary incisors along with a contiguous band of gingiva whereas low smile has less than $75 \%$ of display. In an average smile there is 75 to $100 \%$ display of maxillary incisors with the incisal curvature of the maxillary anterior teeth paralleling the inner curvature of lower lip and may be slightly or totally touching the lower lip.

Nowadays people are concerned more about smile, it is not just a facial expression, but it has a lot of benefits. Smile makes people more attractive, an attractive smile plays a major role in influencing voting and juror decisions, job recruitment and other social interactions. Attractive people are considered to be of a higher social standing, more interesting and more intelligent. Studies show that we are more trustful of others when they smile. In one study done by Scharlemann JPW, et al. [6] participants were more likely to trust another person if they were smiling. This study found that a smile increased people's willingness to trust by about $10 \%$. Attractive smiles not only influence other people's perceptions but also affect the psychosocial well-being of the individual as well as their behavior.

Few publications exist regarding the relationship between gingival visibility and teeth during the smile. In a study of 425 students Crispin BJ and Watson JF 1981 reported that the gingival margin was visible in $66 \%$ of the participants in a natural smile [7]. Tjian AH, et al. [2] in 1984 examined 454 young adults and classified them into 3 categories according to the position of the smile line. The study used the following classification:

1) The smile line is above the cement-enamel junction (gummy smile)

2) The smile line reveals interproximal gingiva

3) The smile line reveals less than $75 \%$ of the anterior maxillary teeth

Class 1 accounted for $10.6 \%$, class 2 accounted for $68.9 \%$ and class 3 accounted for $20.5 \%$ [2]. The conclusion of this study that when patients presented with a gummy smile esthetics was the prime requirement, patients with uncovered interproximal gingiva esthetics were still important and in patients with a smile line under $75 \%$ of anterior maxillary teeth, the impact of esthetics was less.

The perception of esthetics differs from person to person and is influenced by personal experiences and social environments. The most influential factors contributing to a harmonious anterior dentition are the size, shape, and arrangement of maxillary anterior teeth. Lombardi $\mathrm{RE}$ [8] was the first to emphasize the importance of order in dental composition; he was the first to suggest the application of the golden proportion in dentistry. He said that the golden proportion was too strong for use in determining tooth size [8]. Levin EI [9] indicated that the most harmonious issue in tooth to tooth ratio was that of the golden proportion. However, in a recent study it was reported that the golden proportion did not exist between the widths of the maxillary anterior teeth in individuals who have an esthetic smile [10].

Frush and Fisher (2006) were the first to publish the concept of smile arc. While Hulsey (2006) quantified the smile line as ratio to the lower lip, he found that the smile line is an important contributing factor in an attractive smile. Ackerman retitled the "smile line" to "smile arc". Frush and Fisher identified the idea of the buccal corridor spaces, by definition, the buccal corridor spaces were the negative space created between the buccal surfaces of posterior teeth and the inner wall of the cheek. Too much buccal corridor resulted in large empty spaces, while too little looked artificial and was considered the essence of bad prosthetic denture esthetics [11-13].

Gracco A, et al. [12] on the other hand, found that buccal corridor spaces did not contribute significantly to smile esthetics. Kokich VO Jr, et al. [14] used variations of smile esthetics with computer based approach and found that orthodontists, general dentists and lay people had varying levels at which they detected dental discrepancies.

The Occlusal plane represents an important craniofacial point of references, it's established by the incisal surfaces of the anterior teeth and the acclusal surfaces of the posterior teeth [15]. The incisal plane is the anterior portion of the Occlusal plane when viewed from the front, it should be parallel to the horizontal references lines such as inter pupillary line and commissural line to maintain natural facial harmony $[15,16]$.

In dentistry, esthetics is characterized primarily by the smile, however, the smile comprises much more than dental arch. Dental smile design preferences differ from one person to other based on different levels like: social level, economic level, education level and ethnic origin. There is a lack of similar studies in UAE.

\section{Material and Methods}

A questionnaire survey of standardized images of smiles was distributed to 190 dental professionals including 135 under-graduate students at Sharjah University and 190 lay people. A sample size calculation determined the sample as 380 . The participants were not randomly selected and were not a representative sample of the UAE population but a convenience sample.

The participants were all adults above the age of 17 years. The questionnaire had 7 separate aesthetic features with between 3 to 6 different standardized computer generated images for each feature.

The esthetic features of the different smile images 1-7 included the following:

\section{Pilot Study}

A pilot study was planned using the questionnaire on 10 dentists and 10 lay people. Four questions were asked:

1) Did you understand all the questions?

2) Did you understand the aim of the questions?

3) Did you have any problem answering any of the questions?

4) Regarding question (3), if the answer yes, what problem did you have with the questionnaire?

These questions were added to the end of the main smile design questionnaire, All 20 respondents for the pilot questionnaire were recruited from Mohamed Bin Rashid University of Medicine and Health Science. The results of the pilot indicated that none of the respondents had problem answering any of the four questions. Two respondents did not understand the aim of the main questionnaire; a covering explanation letter was distributed to the respondents for the main study. 

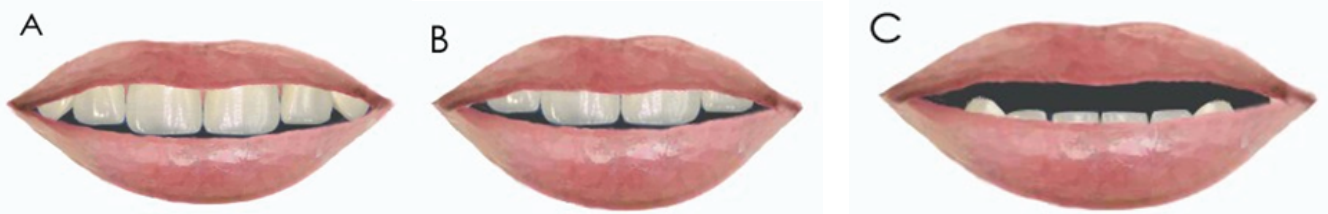

Image 1: Tooth exposure at rest with three images of the amount of tooth exposed at rest (more than half of maxillary teeth only, less than half of maxillary teeth only, mandibular teeth only).
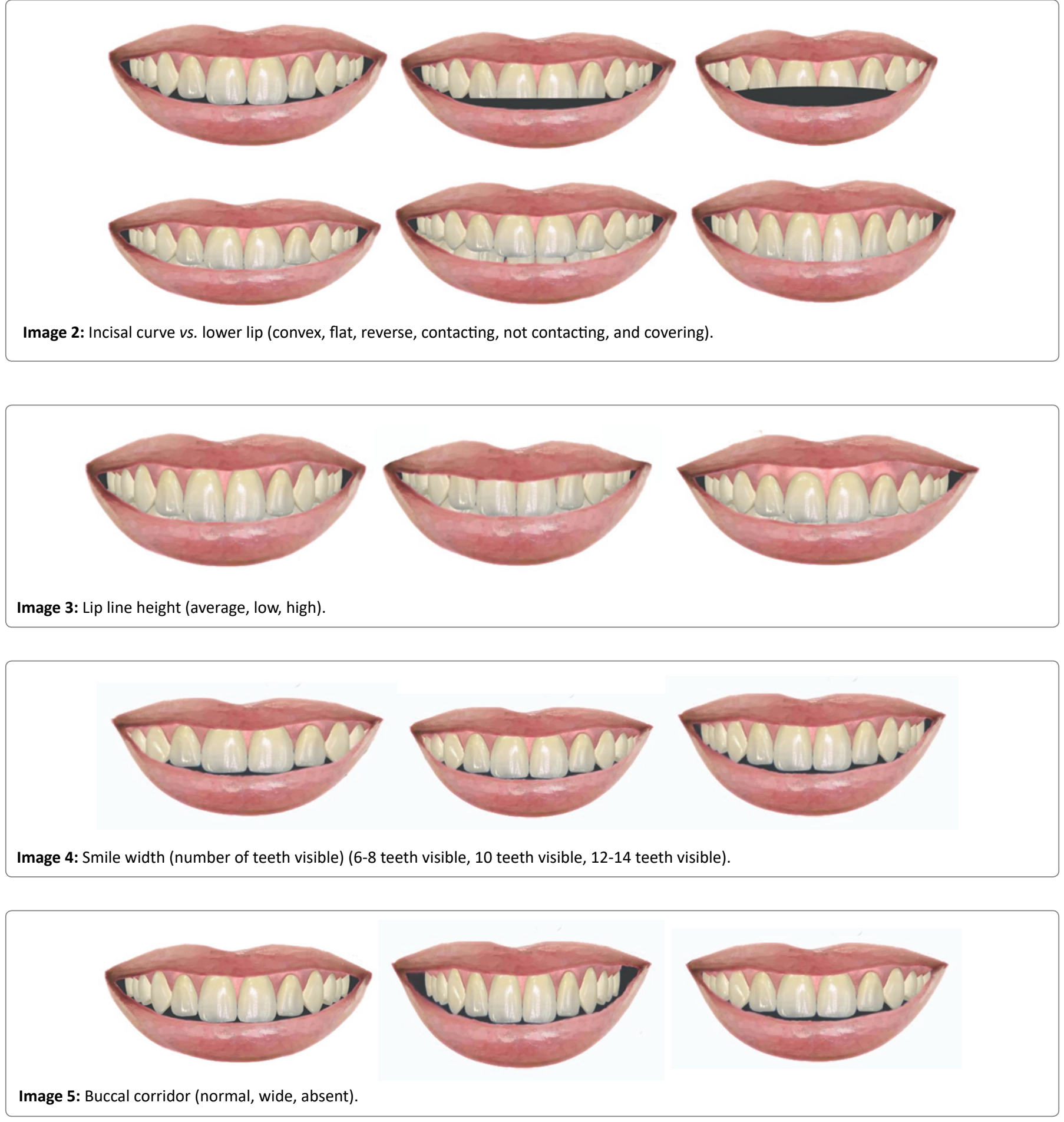


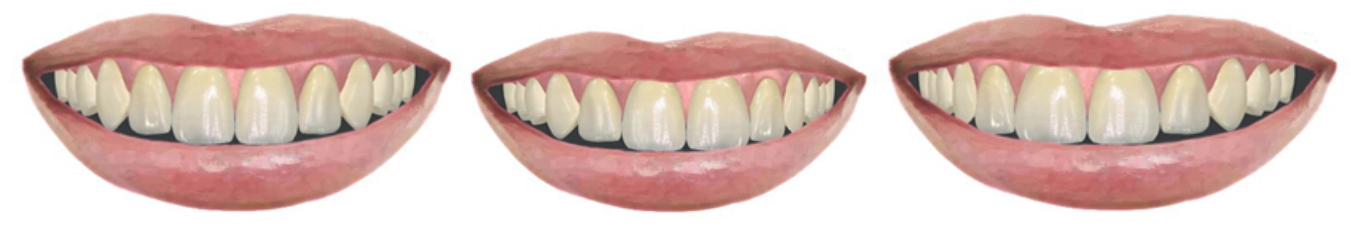

Image 6: Upper inter incisal line vs. facial mid line (coincident, deviated to RT, deviated to left).

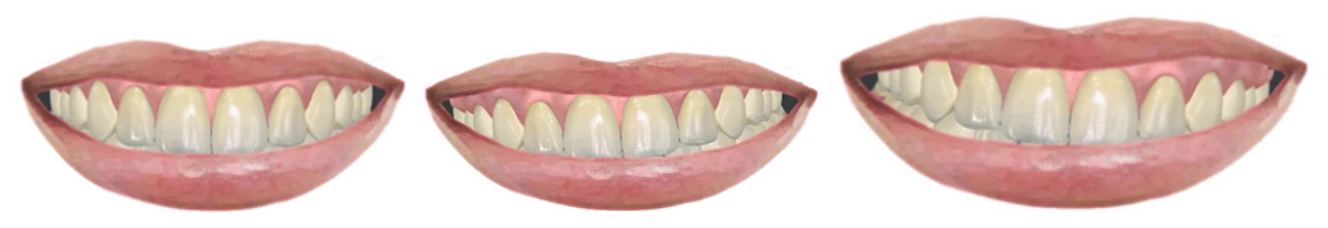

Image 7: Occlusal plane vs. commissural line (parallel, slanted to right, slanted to left).

\section{Results}

\section{Comparison of esthetic features by occupation}

Our study shows that the majority of aesthetic criteria (occlusal tooth exposure at rest, incisal curve vs. the lower lip, smile width, labial corridor and occlusal plane vs. the commissural line) have no significant differences between dental professionals and lay people (Figure 1).

The current study shows that the dental students and qualified dentists preferred the average smile line, while the majority of lay people preferred the low smile line.

The majority of dental students and qualified dentists preferred the upper inter incisal line that coincides with facial midline as expected, while the majority of lay people preferred the upper inter incisal line that deviated to the right of the mid line.

\section{Comparison of esthetic features by city}

The majority of respondents from Abu Dhabi, Dubai and Sharjah preferred the upper inter incisal line that coincided with the midline, while the majority from other Emirates preferred the inter incisal line that deviated to the right of the facial midline (Figure 2).

The analysis revealed that there was no significant difference between unmarried and officially married in evaluating the aesthetic smile criteria. Both groups unmarried and officially married preferred a low smile line.

More married respondents preferred the low lip line whereas unmarried respondents were evenly distributed between those liking an average and low lip line $(\mathrm{p}<0.05)$.

Over half the unmarried respondents had a significantly greater preference for midline coincidence but married respondents were more evenly split regarding this aspect of smile design $(\mathrm{p}<0.05)$ (Table1).

\section{Comparison of esthetic features by gender}

Significantly more females compared to males preferred a convex smile irrespective of whether or not the upper teeth contacted the lower lip $(\mathrm{p}<0.01)$. Females tended to prefer a low lip line compared to males but this was at the borderline of significance $(\mathrm{p}=0.067)$ (Table 2).

\section{Discussion}

Several criteria for aesthetic smile and aesthetic treatment planning have been proposed in the literature. These criteria are crucial for facilitating the work of the dentist and dental laboratory technician.

Considerations of lay people and dentals professionals regarding aesthetic and beauty can be a valuable tool in improving the aesthetic value of restorations, increasing patient satisfaction, and reducing complaints.

This cross-sectional study was designed to evaluate the aesthetic smile preferences between lay people and dental professionals in the UAE.

The use of the questionnaire of images with different aesthetic criteria was done because it is a cost and time effective method. However, there were some complications. As expected, the images needed to be explained especially for the lay people and most of the lay people had difficulty in differentiation between the three categories of question 7 (occlusal plane vs. commissural line).

The pilot study did not identify this problem as the respondents were recruited from the dental college and had dental knowledge and the lay people were probably better informed. Pilot studies should recruit from the target population.

Regarding the age and gender, in this study age was significantly different between the two groups. As the mean age of lay people was 33 years, qualified dentists were 30 years and dental students were 23 years. However, age didn't differ by gender.

According to Hulsey the smile line is an important contributing factor in the attractive smile, while Tjian AH, et al. [2] has classified the smile line into average, high and low smile line.

According to Yoon, et al. studies among dentists and laypeople to examine the attractiveness of the smile by investigating the aesthetic criteria of the smile, shows that the most common attractive smile in regards to smile line was the average (56\%), followed by high smile (29\%) and low smile line (15\%).

The current study supported these findings as dental students and qualified dentists preferred the average smile line, except lay people where the majority preferred the low smile line. 


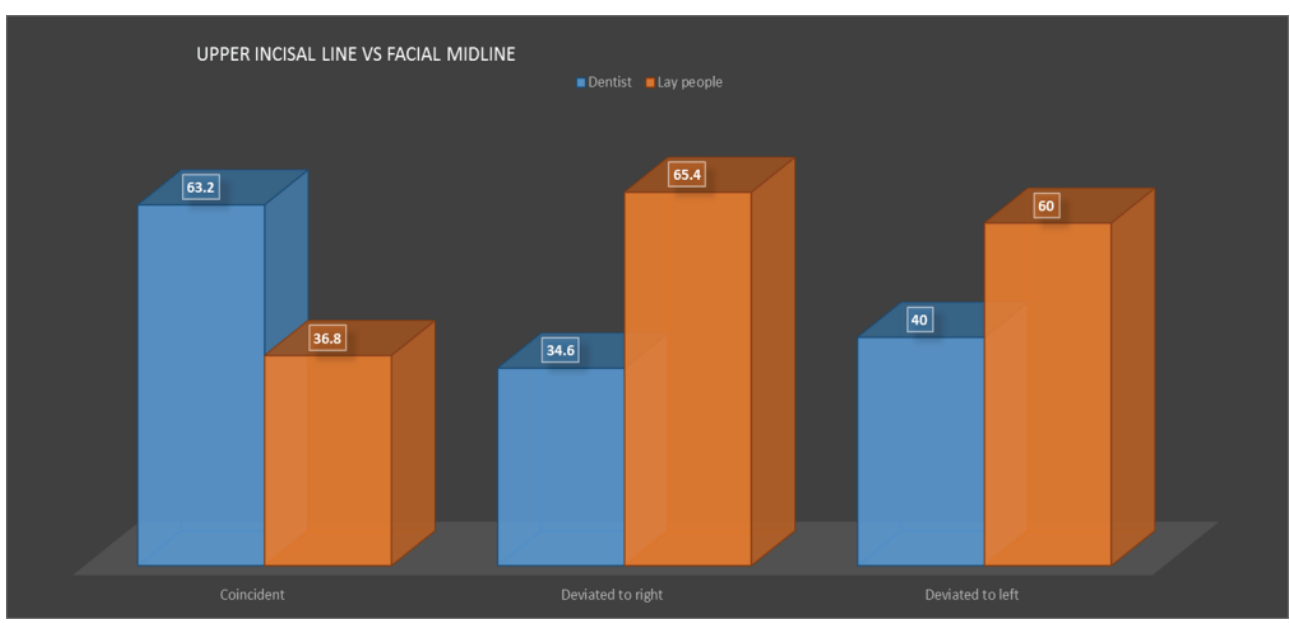

Figure 1: Comparison of esthetic features by occupation.

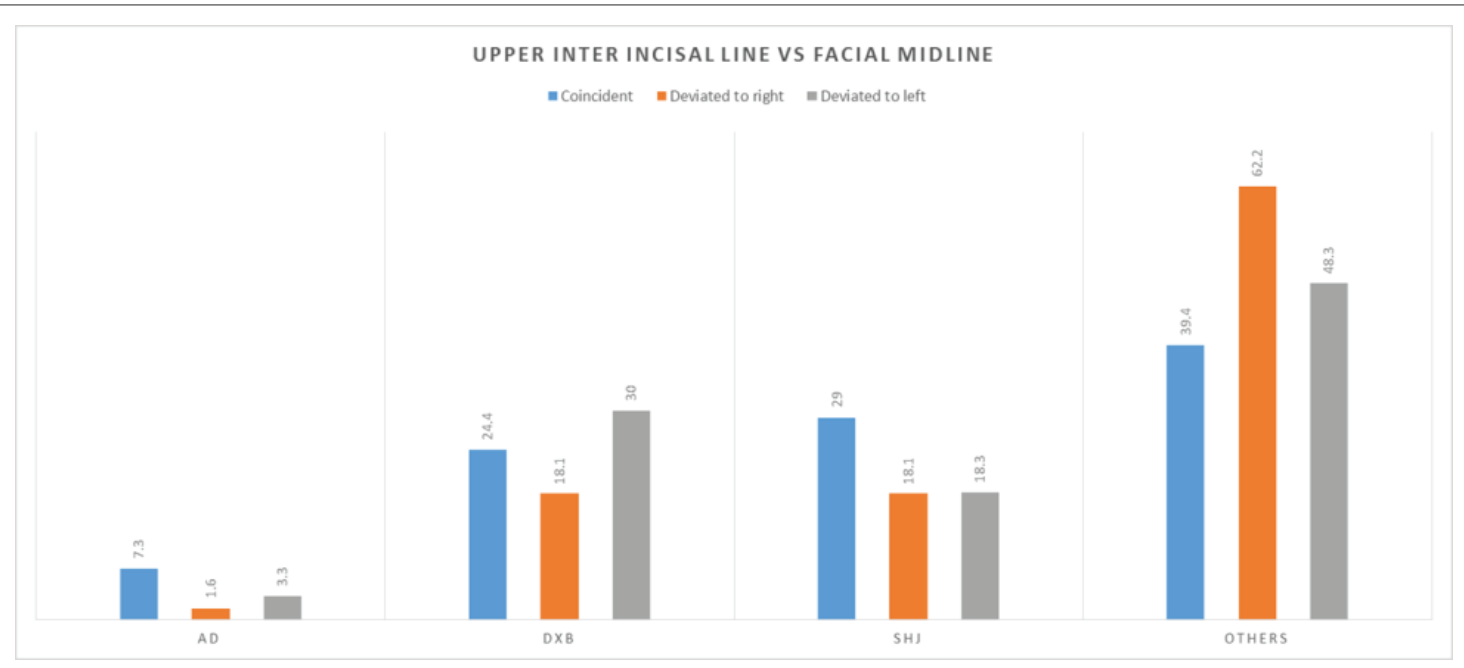

Figure 2: Comparison of esthetic features by city.

According to study done by Yoon, et al. among the dentists and lay people to examine the attractiveness of the smile by investigating the aesthetic criteria of the smile, it was found that the most attractive smile in regards to parallelism of the maxillary anterior incisal curve with the lower lip was parallel smile $(60 \%)$, followed by straight smile (34\%) then the reverse smile (5\%).

The current study supported these findings, that the majority of qualified dentists, students and lay people preferred the parallel smile.

According to study done by Parekh SM, et al. [11] to evaluate the aesthetic acceptability range of computer-generated variations in smile arc and buccal corridor between lay people and orthodontists, the buccal corridor were presented as none, ideal and excessive.

The study showed no significant differences between laypeople and orthodontists on the two variables tested, while orthodontists and lay people both found smiles with excessive buccal corridor to be significantly less acceptable than those with ideal or absent buccal corridor.

Contrary to our expectations, this study shows no significant differences between lay people and dental professionals in terms of buccal corridor, as the two groups preferred the smile with wide buccal corridor rather than normal or absent.

Our study shows significant differences between dental professionals and lay people in terms of upper inter incisal line $v s$. facial midline. The majority of dental students and qualified dentists preferred the upper inter incisal line that coincides with facial midline as expected, while the majority of lay people preferred the upper inter incisal line that deviated to the right of the mid line.

This result was not expected but it might be explained by the findings of Kokich VO Jr, et al. [14] who found that the lay people were not able to detect deviations up to $4 \mathrm{~mm}$.

The result of our study shows that the Occlusal plane which is parallel to the commissural line is most preferred by both dental professionals and lay people. This was proposed by Goldstein RE, et al. [15] and Dawson PE [16] is that the occlusal plane should be parallel to the commissural line to maintain natural facial harmony.

In contrast with the findings of Anderson and Brisman who found some discrepancies between the preferences of dental professionals and laypeople, our study shows that the majority of aesthetic criteria 
Table 1: Comparison of esthetic features by Marital Status.

\begin{tabular}{|c|c|c|c|}
\hline Item & Not Married & Officially Married & p-value \\
\hline \multicolumn{4}{|l|}{ 1. Tooth exposure at rest } \\
\hline a. More than half shown & $138(65.7 \%)$ & $72(34.3 \%)$ & \multirow{3}{*}{.810} \\
\hline b. Less than half shown & $103(63.2 \%)$ & $60(36.8 \%)$ & \\
\hline c. Lowers visible & $4(57.1 \%)$ & $3(42.9 \%)$ & \\
\hline \multicolumn{4}{|c|}{ 2. Incisal curve vs. lower lip } \\
\hline a. Convex & 89 (59.7\%) & $60(40.3 \%)$ & \multirow{6}{*}{.427} \\
\hline b. Flat & $61(68.5 \%)$ & $28(31.5 \%)$ & \\
\hline c. Reverse & $5(50 \%)$ & $5(50 \%)$ & \\
\hline d. Contacting & $22(61.1 \%)$ & $14(38.9 \%)$ & \\
\hline e. Not contacting & $59(71.1 \%)$ & $24(28.9 \%)$ & \\
\hline f. Covering & $9(62.2 \%)$ & $4(30.8 \%)$ & \\
\hline
\end{tabular}

\section{Lip line height}

\begin{tabular}{|l|c|c|}
\hline a. Average & $102(69.9 \%)$ & $44(30.1 \%)$ \\
\hline b. Low & $130(59.6 \%)$ & $88(40.4 \%)$ \\
\hline C. High & $13(81.2 \%)$ & $3(18.8 \%)$ \\
\hline
\end{tabular}

\section{Smile width}

a. 6-8 smile visible

b. 10 visible

(3) $(81.2 \%)$

\section{c. 12-14 visible}

\begin{tabular}{|c|c|}
\hline $51(61.4 \%)$ & $32(38.6 \%)$ \\
\hline $129(69 \%)$ & $58(31 \%)$ \\
\hline $65(59.1 \%)$ & $45(40.9 \%)$ \\
\hline
\end{tabular}

\section{Labial corridor}

\begin{tabular}{|c|c|c|c|}
\hline a. Normal & 59 (65.6\%) & 31 (34.4\%) & \multirow{3}{*}{.524} \\
\hline b. Wide & 123 (66.5\%) & 62 (33.5\%) & \\
\hline c. Absent & 63 (60\%) & 42 (40\%) & \\
\hline
\end{tabular}

\section{Upper inter incisal line vs. facial midline}

\begin{tabular}{|l|c|c|c|}
\hline a. Coincident & $134(69.4 \%)$ & $59(30.6 \%)$ & \multirow{2}{*}{$.023 *$} \\
\cline { 1 - 2 } b. Deviated to right & $81(63.8 \%)$ & $46(36.2 \%)$ & \\
\cline { 1 - 2 } c. Deviated to left & $30(50 \%)$ & $30(50 \%)$ & \\
\cline { 1 - 2 } 7. Occlusal plane vs. Commissural line & & \\
\cline { 1 - 3 } a. parallel & $94(62.7 \%)$ & $56(37.3 \%)$ & .352 \\
\cline { 1 - 2 } b. Slanted to right & $124(67.8 \%)$ & $59(32.2 \%)$ & \\
\cline { 1 - 2 } c. Slanted to left & $27(57.4 \%)$ & $20(42.6 \%)$ & \\
\hline
\end{tabular}

(occlusal tooth exposure at rest, incisal curve vs. the lower lip, smile width, labial corridor and occlusal plane vs. the commissural line) have no significant differences between dental professionals and lay people. The smile line and inter incisal line $v s$. the facial midline were the only exceptions to this.

Dental professionals and lay people seem to have similar preferences when evaluating the attractiveness of smiles, this supports the theory that the level of dental-related education has little influence on the perception and judgment of dental aesthetics 40 .

This study shows that there is no cultural-related differences between different UAE cities in all esthetic criteria except the inter incisal line vs. facial midline which shows that the people from Abu Dhabi, Dubai and Sharjah preferred the inter incisal line that coincides with the facial midline while people from other cities preferred the inter incisal line that deviated to the right of the midline. Marital status does not affect the esthetic preferences in this study.

A person's ability to recognize a beautiful smile is innate and the perception of attractiveness is an individual preference. This research identified certain variables that people consider in their assessment of the attractive smile.
Table 2: Comparison of esthetic features by Gender.

\begin{tabular}{|c|c|c|c|}
\hline Item & Male & Female & p-value \\
\hline \multicolumn{4}{|l|}{ 1. Tooth exposure at rest } \\
\hline a. More than half shown & 82 (39\%) & $128(61 \%)$ & \multirow{3}{*}{.227} \\
\hline b. Less than half shown & 65 (39.9\%) & $98(60.1 \%)$ & \\
\hline c. Lowers visible & $5(71.4 \%)$ & $2(28.6 \%)$ & \\
\hline \multicolumn{4}{|l|}{ 2. Incisal curve vs. lower lip } \\
\hline a. Convex & $52(34.9 \%)$ & 97 (65.1\%) & \multirow{6}{*}{$.009 *$} \\
\hline b. Flat & $49(55.1 \%)$ & 40 (44.9\%) & \\
\hline c. Reverse & $6(60 \%)$ & $4(40 \%)$ & \\
\hline d. Contacting & $15(41.7 \%)$ & $21(58.3 \%)$ & \\
\hline e. Not contacting & $27(32.5 \%)$ & $56(67.59 \%)$ & \\
\hline f. Covering & $3(23.1 \%)$ & $10(76.9 \%)$ & \\
\hline \multicolumn{4}{|l|}{ 3. Lip line height } \\
\hline a. Average & $66(45.2 \%)$ & $80(54.8 \%)$ & \multirow{3}{*}{.067} \\
\hline b. Low & 77 (35.3\%) & $141(64.7 \%)$ & \\
\hline C. High & $9(56.2 \%)$ & $7(43.8 \%)$ & \\
\hline \multicolumn{4}{|l|}{ 4. Smile width } \\
\hline a. 6-8 smile visible & $29(34.9 \%)$ & $54(65.1 \%)$ & \multirow{3}{*}{.304} \\
\hline b. 10 visible & $82(43.9 \%)$ & $1058(56.1 \%)$ & \\
\hline c. $12-14$ visible & $41(37.3 \%)$ & $69(62.7 \%)$ & \\
\hline \multicolumn{4}{|l|}{ 5. Labial corridor } \\
\hline a. Normal & $43(47.8 \%)$ & $47(52.2 \%)$ & \multirow{3}{*}{.224} \\
\hline b. Wide & $69(37.35 \%)$ & $116(62.7 \%)$ & \\
\hline c. Absent & 40 (38.1\%) & 65 (61.9\%) & \\
\hline \multicolumn{4}{|c|}{ 6. Upper inter incisal line vs. facial midline } \\
\hline a. Coincident & $83(43 \%)$ & $110(57 \%)$ & \multirow{3}{*}{.460} \\
\hline b. Deviated to right & $46(36.2 \%)$ & $81(63.82 \%)$ & \\
\hline c. Deviated to left & $23(38.3 \%)$ & $37(61.7 \%)$ & \\
\hline \multicolumn{4}{|c|}{ 7. Occlusal plane vs. Commissural line } \\
\hline a. parallel & $54(36 \%)$ & $96(64 \%)$ & \multirow{3}{*}{.352} \\
\hline b. Slanted to right & $76(41.5 \%)$ & $107(58.5 \%)$ & \\
\hline c. Slanted to left & $22(46.8 \%)$ & $25(53.2 \%)$ & \\
\hline
\end{tabular}

The importance of potential patient's perception about aesthetic treatment cannot be overemphasized because it is the patients who receive treatment and need to gain satisfaction from improved aesthetics and function.

\section{Conclusion and Recommendations}

Beauty must be studied and evaluated to improve the quality of treatment provided to dental patients. The opinions and perceptions of lay people and dental professionals regarding beauty and attractiveness of the smile were similar, except two variables, which smile line and the relation were of inter incisal line to the facial mid line.

The majority of lay people and dental professionals preferred more than half the tooth to be shown at rest, an incisal curve which is convex to the lower lip, smile width with ten visible teeth, a wide labial corridor and an Occlusal plane that is parallel to the commissural line. This can be considered as the preferred esthetic smile among the UAE community.

The significant differences between lay people and dental professionals in this study was in smile line height, where the lay people preferred a low smile line and dental professionals preferred an average smile line. 
Other significant differences between lay people and dental professionals in this study was regarding the inter incisal line related to the facial midline, which shows that dental professionals preferred inter incisal line to coincide with the midline while lay people preferred the inter incisal line that deviated to the right of the facial midline.

\section{Conflict of Interest}

The authors confirm that this article content has no conflict of interest.

\section{Acknowledgements}

I have the pleasure to write a few words of acknowledgement. I would like to express my gratitude to my supervisors Dr. Moosa Abuzayda, and Dr. Amar Hassan for the statistical analyses. I need to express my gratitude and deep appreciation to Prof. Wael Att who assisted, advised and supported my research, also many thanks goes to him for introducing the research questionnaire as well.

I would like to thank Dr. Suhail AlAmad for his assistant in questionnaire distribution in Sharjah University as he is member of the research ethical committee in Sharjah University.

\section{References}

1. Newton JT, Parbhu N, Robinson PG (2003) The Impact of Dental Appearance on the Appraisal of Personal Characteristics. Int J Prosthodont 16: 429-434.

2. Tjian AH, Miller GD, The JG (1984) Some esthetic factors in a smile. J Prosthet Dent 51: 24-28.

3. Qualtrough AJ, Burke FJ (1994) A look at dental esthetics. Quintessence Int 25: 7-14.

4. Morly J, Eubark J (2001) Macroesthetic Elements of Smile Design. J Am Dent Assoc 132: 39-45.
5. Silberberg N, Goldsttein M, Smidt A (2009) Excessive gingival display-etiology, diagnosis and treatment modalities. Quintessence Int 40: 809-818.

6. Scharlemann JPW, Eckel CC, Kacelnik A, Wilson RK (2001) The value of a smile: Game theory with a human face. J Econ Psychol 5: 617-640.

7. Crispin BJ, Watson JF (1981) Margin placement of esthetic veneer crowns. Part II: Posterior tooth visibility. J Prosthet Dent 45: 389-391.

8. Lombardi RE (1973) The principles of visual perception and their clinical application to denture esthetics. J Prosthet Dent 29: 358382.

9. Levin El (1978) Dental esthetics and the golden proportion. J Prosthet Dent 40: 244-252.

10. Preston JD (1993) The golden proportion revisited. J Esthet Dent 5: 247-251.

11. Parekh SM, Fields HW, Beck FM, Rosenstiel S (2006) Attractiveness of variations in the smile arc and buccal corridor space as judged by orthodontists and laymen. Angle Orthod 76: 557-563.

12. Gracco A, Cozzani M, D'Elia L, Manfrini M, Peverada C, et al. (2006) The smile buccal corridors: aesthetic value for dentists and laypersons. Prog Orthod 7: 56-65.

13. Holm S (1979) A Simple Sequentially Rejective Multiple Test Procedure. Scand J Stat 6: 65-70.

14. Kokich VO Jr, Kiyak HA, Shapiro PA (1999) Comparing the perception of dentists and lay people to altered dental esthetics. J Esthet Dent 11: 311-324.

15. Goldstein RE, Belinfante L, Nahai F (1997) Change Your Smile. $3^{\text {rd }}$ Edition, Quintessence, USA.

16. Dawson PE (1989) Evaluation, Diagnosis and Treatment of Occlusal Problems. $2^{\text {nd }}$ Edition, Mosby 365-381. 